\title{
Cork-polymer biocomposites: Mechanical, structural and thermal properties
}

\author{
Emanuel M. Fernandes*, Vitor M. Correlo, João F. Mano, Rui L. Reis \\ 3B's Research Group - Biomaterials, Biodegradables and Biomimetics, University of Minho, Headquarters of the European Institute of Excellence on Tissue Engineering \\ and Regenerative Medicine, AvePark, 4806-909 Taipas, Guimarães, Portugal \\ ICVS/3B's - PT Government Associate Laboratory, Braga/Guimarães, Portugal
}

\section{A R T I C L E I N F O}

Article history:

Received 24 February 2015

Revised 7 May 2015

Accepted 18 May 2015

Available online 21 May 2015

\section{Keywords:}

Cork

Sustainable composites

Biocomposites

Eco-friendly

Mechanical properties

Thermal properties

\begin{abstract}
A B S T R A C T
This work addresses to the preparation of biocomposites resulting from the combination of different biodegradable aliphatic polyesters with cork (30 wt.\%). The lignocellulosic biomass with closed cellular structure was compounded with poly(L-lactic acid) (PLLA), polyhydroxybutyrate-co-hydroxyvalerate

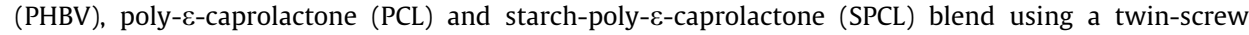
extruder prior to injection moulding into tensile samples. The physico-mechanical and thermal properties of the matrices and the bio-based cork composites were investigated. This study shows that the addition of cork contributes to produce lightweight materials using PLLA and PHBV matrices and promotes an increase on the stiffness of PCL. The fracture morphology observations showed good physical cork-matrix bonding with absence of voids or cavities between cork and the bio-based polyesters. Cork increases the crystallinity degree of the biocomposites. These findings suggest that the cork-polymer biocomposites are a viable alternative to develop more sustainable composite materials, such as automotive interior parts and bio-based caps for wine bottles as it has been shown as proof-of-concept.
\end{abstract}

(c) 2015 Elsevier Ltd. All rights reserved.

\section{Introduction}

Lignocellulosic biomass represents a renewable, biodegradable, lightweight, abundant and cheap source of raw materials, making them attractive for the development of sustainable products [14]. Cork is the outer bark of an oak tree known botanically as Quercus suber L.; being the major chemical constituents suberin (33-50\%); lignin (13-29\%); polysaccharides, (6-25\%); and extractives (8.5-24\%) [5,6]. Cork reveals an anisotropic closed cellular structure as shown in Fig. 1.

It is composed of an aggregate of cells, about 42 million per cubic centimetre [7]. Cork is a lightweight material, viscoelastic and impermeable to liquids or gases, good thermal, acoustic and electrical insulator, sound and vibration insulator and exhibits a near-zero Poisson coefficient, which found applications from the stoppers, agglomerates to aeronautics [5,8-12]. Furthermore, cork composites are one of the most promising fields of cork technology [8]. The combination of cork with polymers trough melt based technologies brought added-value to cork based materials that

* Corresponding author at: 3B's Research Group - Biomaterials, Biodegradables and Biomimetics, University of Minho, AvePark, Zona Industrial da Gandra, 4806909 Caldas das Taipas, Portugal.

E-mail address: efernandes@dep.uminho.pt (E.M. Fernandes). can promote the development of a wide range of innovative applications. Studies can be found on the combination of cork and cork by-products with polyolefins such as polyethylene (PE) and polypropylene (PP) and the effect of adding coupling agent in the mechanical properties [13-15], chemical surface modification to improve cork-polymer compatibility [16,17]; cork in sandwich composite structures [18-20] and hybrid cork composite reinforced with natural fibres [21,22]. Recently, the combination of the unique properties of cork with biodegradable matrices $[23,24]$ was also studied aiming the production of more sustainable materials. A sustainable product is a product which will gives as little impact on the environment as possible during its life cycle [25]. Nevertheless, one of the main drawbacks pointed to composites is the low sustainability due to the separation problems of the mixed materials [25]. One interesting approach is to consider the re-manufacturing of old products or the use of biodegradable polymers, as matrices, combined usually with biofibres as the reinforcing element, to produce fully biodegradable materials, the so called biocomposites or green composites [1,26].

Biodegradable polymers and bio-based plastic products from renewal resources can form sustainable and eco-friendly products than can compete in the current market $[2,27,28]$. According to the market data compiled by European Bioplastics, the global production capacity of bio-based plastics is predicted to quadruple from 


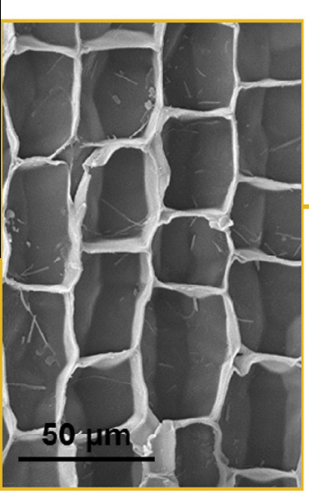

NR direction

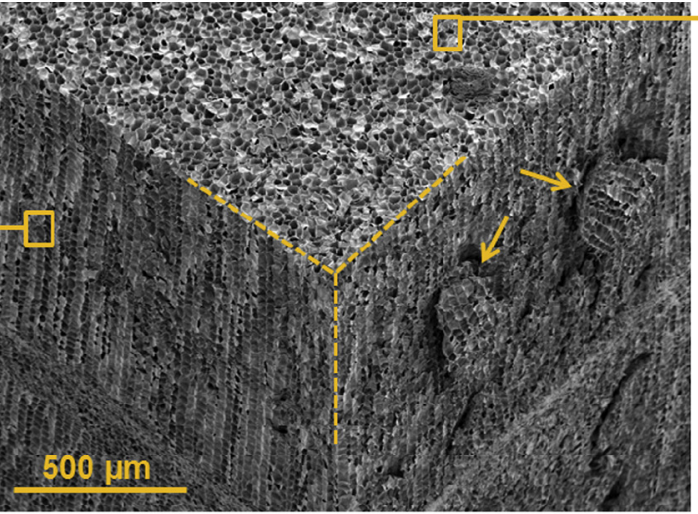

3D - Cork Structure

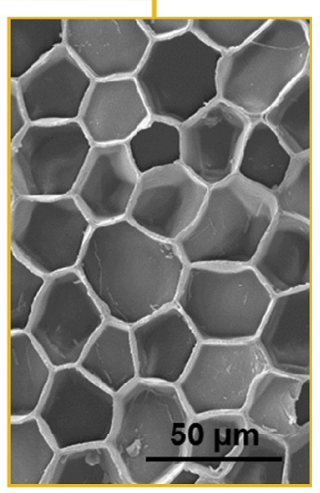

$\mathbf{R}$ direction

Fig. 1. SEM micrographs of the 3D cork morphology showing in detail the non-radial direction (NR) and radial direction (R).

around 1.6 million tonnes in 2013 to approximately 6.7 million tonnes by 2018 [29]. The different biodegradable polymers can be divided into 4 classes [30]: The agro-polymers (e.g. polysaccharides) obtained from biomass by fractionation such as starch and lignocellulosic products. The second and third are polyesters, obtained, respectively by fermentation from biomass or from genetically modified plants (e.g. polyhydroxyalkanoates (PHAs), including polyhydroxybutyrate (PHB)) and by synthesis from monomers obtained from biomass (e.g. polylactic acid (PLA)). The fourth family are polyesters, totally synthesized by the petrochemical process (e.g. polycaprolactone (PCL)) $[1,4,30]$. The interest on these biodegradable polymers has grown, since they present similar mechanical and thermal properties as compared with synthetic thermoplastic such as polyethylene (PE) and polypropylene (PP) [31]. The PLA and PHB reveal higher mechanical properties, with a modulus around $2.8-3.4 \mathrm{GPa}$ and $1.0-2.1 \mathrm{GPa}$, respectively $[2,3,32]$. The aliphatic polyesters present proper mechanical and degradation properties that make them good candidates to replace traditional polymers on several applications [26].

Vilela et al. [24], showed that cork residues or chemically modified can be valorised when combined with PLA and PCL and processed by melt mixer followed by injection moulding. The developed biocomposites revealed benefits in terms of weight reduction. The aim of this study was to produce and characterize several biocomposites prepared by combining different matrices from renewable resource including, poly(L-lactic acid), (PLLA); poly hydroxybutyrate-co-hydroxyvalerate, (PHBV); PCL and starch-poly- $\varepsilon$-caprolactone (SPCL), with granulated cork. The biocomposites were compounded through twin-screw extrusion and further processed by injection moulding. We demonstrate that by combining proper melt based technologies this study can provide information for basic properties of several cork biocomposites with potential application in new products from leisure products, to automotive and building sectors.

\section{Materials and methods}

\subsection{Cork and polymer materials}

Cork granules, with an average particle size $0.5-1 \mathrm{~mm}$, specific weight of $166 \pm 21 \mathrm{~kg} \mathrm{~m}^{-3}$ and moisture of $\sim 7.5 \%$ was supplied by Amorim Revestimentos S.A. (S. Paio Oleiros, Portugal). The polymers used in the preparation of the cork based composites includes: (i) PLLA with a L-lactide content of $99.6 \%$ and a $M_{w}$ of $69,000 \mathrm{~g} \mathrm{~mol}^{-1}$, was obtained from Cargill Dow LLC, USA; (ii) PHBV polymer with $12 \% \mathrm{HV}$ content and molecular weight $\left(M_{w}\right)$ of $\sim 425,692 \mathrm{~g} \mathrm{~mol}^{-1}$ was provided by PHB Industrial, Serrana,
Brazil; (iii) PCL resin (commercially available as $\mathrm{TONE}^{\circledR} 787$ ), with $M_{w}$ of $125,000 \mathrm{~g} \mathrm{~mol}^{-1}$, was obtained from Union Carbide Chemicals and Plastics Division, New Jersey, USA and (iv) A blend of corn starch with PCL (SPCL) containing about 63 wt.\% of PCL, $27 \mathrm{wt} . \%$ of corn starch and $10 \mathrm{wt} . \%$ of natural plasticizers was supplied by Novamont, Italy. The $M_{w}$ of PCL present in this blend is about $118,000 \mathrm{~g} \mathrm{~mol}^{-1}$.

\subsection{Twin-screw extrusion compounding}

Prior to compounding, all natural raw materials were pre-dried at 40 (i.e. PCL and SPCL) to $70^{\circ} \mathrm{C}$ (i.e. PLLA; PHBV and cork) during $24 \mathrm{~h}$ for moisture content stabilization. All the polymers were thereafter reduced to a grain size less than $0.5 \mathrm{~mm}$ in an Ultra centrifugal mill from Retsch. The prepared compositions and processing conditions are summarized in Table 1.

The raw materials were pre-mixed and further compounded in a Rondol SCF modular co-rotating twin-screw extruder (TSE) with the screws diameter of $16 \mathrm{~mm}$, a length to diameter ratio $(L / D)=25$ and a single strand die of $3 \mathrm{~mm}$. The mixture was placed in the hopper and automatically feeded at a constant rate with a volumetric dosing unit from SHINI Plastics Technologies (Germany). The temperature profile along the barrel to the die was set according to the information present in Table 1 with the rotation screws at $50 \mathrm{rpm}$. Part of the extrudate was cooled in water bath and subsequently ground by a lab pelletizer SCHEER (Stuttgart) to produce composite pellets with length $\leqslant 5 \mathrm{~mm}$ suitable for injection moulding. Prior to this step, the produced pellets were dried in a vacuum oven at $50{ }^{\circ} \mathrm{C}$ until stabilize.

Table 1

Compositions and processing conditions of the polymer matrices and the bio-based composites with $30 \mathrm{wt}$.\% of cork

\begin{tabular}{|c|c|c|c|c|}
\hline \multirow[b]{2}{*}{$\begin{array}{l}\text { Sample } \\
\text { code }\end{array}$} & \multicolumn{2}{|c|}{$\begin{array}{l}\mathrm{CPC}^{\mathrm{a}} \\
\text { composition } \\
\text { (wt.\%) }\end{array}$} & \multirow{2}{*}{$\begin{array}{l}\text { Extrusion } \\
\text { Temperature profile } \\
\left({ }^{\circ} \mathrm{C}\right)\end{array}$} & \multirow{2}{*}{$\begin{array}{l}\text { Injection moulding } \\
\text { Temperature max. } \\
\left({ }^{\circ} \mathrm{C}\right)\end{array}$} \\
\hline & Polymer & Cork & & \\
\hline PLLA & 100 & 0 & $\begin{array}{l}110 ; 160 ; 175 ; 175 ; \\
170\end{array}$ & 170 \\
\hline PLLA/Cork & 70 & 30 & & 175 \\
\hline PHBV & 100 & 0 & $\begin{array}{l}110 ; 150 ; 175 ; 175 ; \\
180\end{array}$ & 175 \\
\hline PHBV/Cork & 70 & 30 & & 180 \\
\hline PCL & 100 & 0 & $40 ; 60 ; 70 ; 75 ; 80$ & 90 \\
\hline PCL/Cork & 70 & 30 & & \\
\hline SPCL & 100 & 0 & $30 ; 60 ; 70 ; 75 ; 80$ & 90 \\
\hline SPCL/Cork & 70 & 30 & & \\
\hline
\end{tabular}

a $\mathrm{CPC}$ : cork-polymer composite. 


\subsection{Injection moulding}

The neat polymers and the biocomposite pellets were injection moulded in a Ferromatik-Milacron K85 (Germany) with $850 \mathrm{kN}$ of clamping force. The injection-moulded specimens were tensile bars produced according ASTM 638, with $60 \mathrm{~mm}$ length, a constant rectangular cross-section of $2 \times 4 \mathrm{~mm}^{2}$, and a neck length of $20 \mathrm{~mm}$. The produced samples were placed in polyethylene plastic bags and conditioned at ambient temperature.

\subsection{Biocomposites density}

The density of the bio-based injection moulded specimens was determined according to the standard ASTM D 792, using an analytical balance equipped with a stationary support for the immersion vessel using liquid propanol. Fives specimens were measured per condition.

\subsection{Mechanical properties}

Tensile properties of the injection moulded specimens, before and after water and soil degradation tests, were measured using an Instron 4505 Universal Machine, (USA) according to the standard ASTM D 638. The tests were conducted using a $1 \mathrm{kN}$ load cell, with a gauge length of $20 \mathrm{~mm}$ and a crosshead speed of $5 \mathrm{~mm} \mathrm{~min}^{-1}$ until rupture. The tensile force was taken as the maximum stress in the stress-strain curve. Tensile modulus was estimated from the initial slope of the stress-strain curve (between $0.5 \%$ and $1 \%$ strain) using the linear regression method. Samples were conditioned at room temperature for at least $48 \mathrm{~h}$ before testing. The average and standard deviations were determined using 5 specimens per condition.

\subsection{Morphology}

The morphological characterization of the cork structure was examined using a NanoSEM 200 FEI (The Netherlands) scanning electron microscope (SEM).

The morphological characterization of the developed biocomposites fracture surface obtained after mechanical tests was performed using a Leica-Cambridge S-360 (UK) scanning electron microscope. In both analyses all the samples were mounted on aluminium stubs with carbon tape and then sputter coated with gold to make them conductive before being analysed.

\subsection{Thermal properties}

Thermogravimetric analyses (TGA) were performed to understand the degradation characteristics of the developed composites and their matrices. The thermal stability was determined using a TGA Q500 series thermogravimetric analyser (TA Instruments, USA). Experiments were performed in platinum pans, at a heating rate of $10^{\circ} \mathrm{C} \mathrm{min}^{-1}$ from $50{ }^{\circ} \mathrm{C}$ to $600{ }^{\circ} \mathrm{C}$ under nitrogen atmosphere. All tests were repeated once.

Differential scanning calorimetry (DSC) measurements of all moulded specimens were assessed by DSC in a Pyris Diamond system (Perkin-Elmer) at $20^{\circ} \mathrm{C} \mathrm{min}^{-1}$ under nitrogen atmosphere. The DSC scans were performed in bulk specimens cut from the central part of the rectangular cross-section of the tensile specimens. The glass transition temperature $\left(T_{g}\right)$, cold crystallization temperature $\left(T_{c c}\right)$, melting temperature $\left(T_{m}\right)$ and total enthalpy $(\Delta H)$ of all injection moulded materials were identified. The degree of crystallinity $\left(\chi_{c}\right)$ was calculated on the basis of a $100 \%$ crystalline a melting enthalpy of $\left(\Delta H_{m}^{0}\right)$ of the used polymer and according to Eq. (1):

$\chi_{c}(\%)=\left(\Delta H_{\mathrm{rec}}+\Delta H_{m}\right) / \Delta H_{m}^{0}(1-w) \times 100$ where $\Delta H_{c c}$ is the enthalpy of cold crystallization before melting; $\Delta H_{m}$ the enthalpy of melting and $w$ is the weight fraction of the non-polymeric part in the composite. All the samples were repeated at least once.

\section{Results and discussions}

\subsection{Density}

Fig. 2(a) illustrates biocomposites with $30 \mathrm{wt}$.\% of granulated cork and the bio-based polyester specimens after injection moulding, while Fig. 2(b) shows the biocomposite pellets of SPCL/Cork after extrusion. In addition, as proof of concept, biodegradable cork composite caps for wine bottles were produced by injection moulding as shown in Fig. 2(c).

The biocomposites reveals good aesthetic properties promoted by the cork as compared with the traditional polystyrene (PS) caps and also the possibility to be coloured with pigments. Thus, cork combined with bio-based matrices can result in a new 100\% natural solution with new complex designs.

The density of the injection moulded specimens was determined in order to evaluate the effect of adding $30 \mathrm{wt} . \%$ of granulated cork to the biodegradable aliphatic polyesters. As observed in Fig. 3, the addition of cork promoted a decrease of $3.9 \%$ and $1.7 \%$ on the density of the biocomposites prepared, respectively, with PLLA and PHBV. This behaviour is ascribed to the lower density of cork (i.e. $166 \pm 21 \mathrm{~kg} \mathrm{~m}^{-3}$ ) as compared with the used matrices. Lower density of the cork filled biocomposites can result in increased specific mechanical properties (property/density).

Moreover, features such as, reduced weight, increased amount of renewable material, reduced material costs and the possibility to recycle are of considerable importance in the several industries (e.g. automotive). On the contrary, adding cork to PCL matrix promoted an increase of $4.5 \%$ on density of the final biocomposite. This result may be ascribed by the lower density of the unfilled PCL and by the shear produced in the twin-screw extrusion followed by the pressure applied in the injection moulding processes. As demonstrated before in the processing of cork with thermoplastic matrices [15], the addition of cork increases highly the melt viscosity reducing the melt flow index. Thus, the two melt based processes may lead to some densification of the cork cells resulting in a higher density.

Nevertheless, by comparing the effect of adding 30 wt.\% of starch to PCL (i.e. SPCL blend) and the same weight fraction of cork to the same polyester (PCL/Cork composite) on the final density, it is possible to observe that cork allows the production of lighter materials than starch $(\sim 5.1 \%$ lighter $)$. This result reveals that the use of cork can be an environmental friendly approach to reduce the cost and promote aesthetic without compromise significantly the density of the PCL.

\subsection{Mechanical properties}

The tensile properties of the injection moulded biodegradable aliphatic polyesters and the biocomposites before biodegradation essays are shown in Fig. 4.

Additionally, Table 2 indicates the values and standard deviations of the tensile properties including tensile strength, tensile modulus and the maximum strain of the materials. Two distinct groups of materials could be identified from these data. PLLA and PHBV present considerable higher stiffness and tensile strength as compared with the PCL or SPCL specimens. In opposite sides, PLLA has brittle properties, i.e. low maximum strain at break, while PCL reveals a ductile behaviour with low tensile modulus and higher strain at break. The addition of cork promoted a decrease 


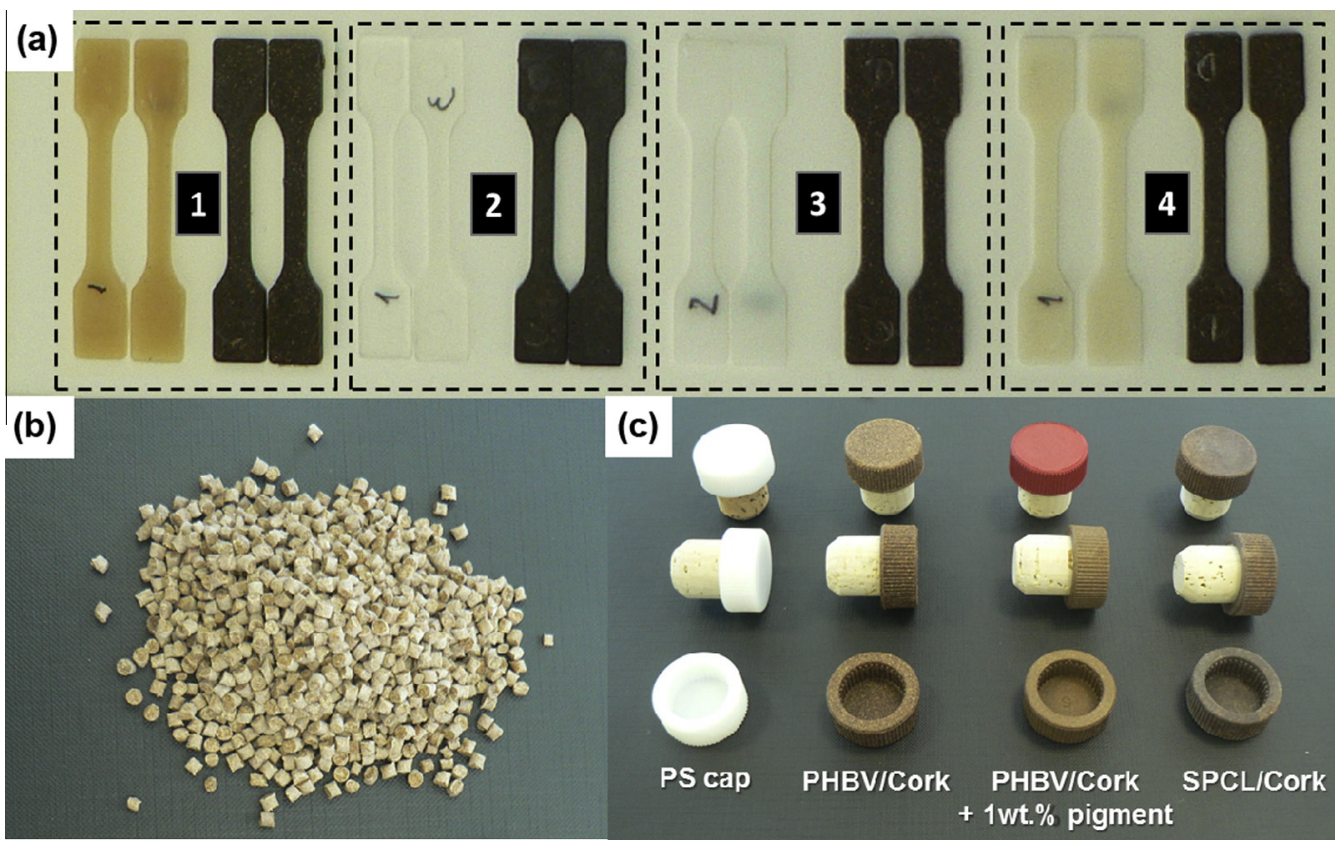

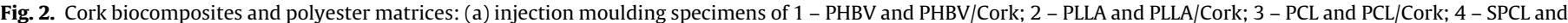
SPCL/Cork; (b) SPCL/Cork (70/30 wt.\%) pellets and (c) polystyrene (PS) and cork biocomposites as caps for wine bottles.

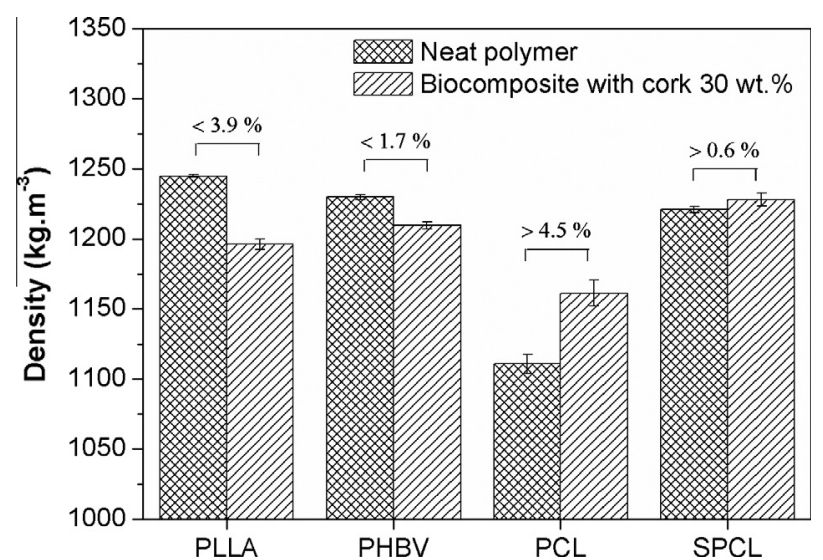

Fig. 3. Density of the polymer matrices and the bio-based composites containing 30 wt.\% of cork.

in the tensile strength of all compositions. This decrease was more pronounced on the biocomposites prepared with PLLA. One possible explanation is the lower mechanical properties of cork as compared with the PLLA and the lower interfacial adhesion of cork with the matrix. Previous studies $[13,21,22]$ performed using polyolefins as matrices, have shown that the tensile strength of corkpolymer composites (CPC) is manly dependent of three parameters: (i) the type of matrix; (ii) the compatibility between polymeric matrix and cork and (iii) cork content, whereas the tensile modulus is influenced by the cork content and processing conditions.

It should be also highlighted that, when natural cork is under tensile load in radial direction, the fracture occurs at stress values of about $1.1 \mathrm{MPa}$, corresponding to a strain of about $8 \%$ [6]. Moreover, the reduced strength of cork contributes to an inferior stress transfer between the cork-matrix and consequent lower mechanical properties.

It was also observed that the addition of cork to PLLA and PHBV reduces the tensile modulus probably due to the lower stiffness of
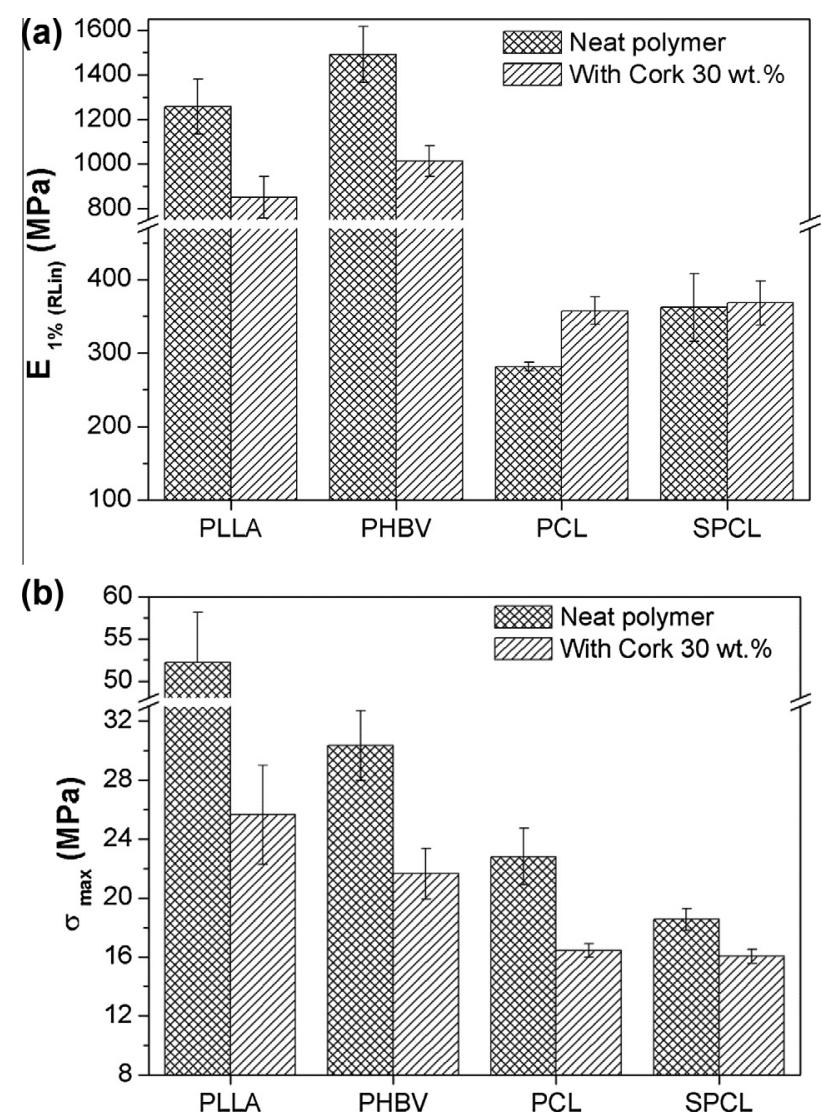

Fig. 4. Mechanical properties of the neat polymers and the biocomposite materials under tensile load: (a) tensile modulus (MPa) and (b) maximum tensile strength (MPa).

cork as compared with the neat polyesters. The effect of the elasticity of cork particles was observed in PHBV biocomposite, were the reduction of stiffness was followed by a slight increase of the strain 
Table 2

Physical properties of the used biodegradable polyesters, and corresponding biocomposites with cork.

\begin{tabular}{|c|c|c|c|c|c|c|c|c|}
\hline Property & PLLA & PLLA/Cork & PHBV & PHBV/Cork & PCL & PCL/Cork & SPCL & SPCL/Cork \\
\hline Tensile strength (MPa) & $52.2(5.9)$ & $25.7(3.3)$ & $30.3(2.4)$ & $21.6(1.7)$ & $22.8(1.9)$ & $16.4(0.4)$ & $18.5(0.7)$ & $16.0(0.5)$ \\
\hline Tensile modulus (MPa) & $1256.6(123.2)$ & $850.6(92.6)$ & $1490(125.8)$ & $1012.4(68.8)$ & $281.4(6.0)$ & $375.2(18.6)$ & $362.0(46.4)$ & $368.3(30.1)$ \\
\hline Strain at break (\%) & $5.5(1.4)$ & $3.4(1.3)$ & $2.9(0.2)$ & $3.8(0.5)$ & $>200$ & $9.10(0.3)$ & $10.3(0.4)$ & $7.0(0.5)$ \\
\hline Density $\left(\mathrm{kg} / \mathrm{m}^{3}\right)$ & $1244.9(1.0)$ & $1196.3(3.7)$ & $1229.9(1.8)$ & $1209.6(2.5)$ & $1110.8(6.5)$ & $1161.2(9.2)$ & $1221.0(2.4)$ & $1228.2(4.6)$ \\
\hline
\end{tabular}

() standard deviation value.

at break. In general, the modulus of a composite material is also related with the density of the obtained material, increasing with the increase of the density. Since cork is a foamed material, its tensile modulus is much lower, that the used bio-based polyesters: around 23.9-31.7 MPa depending of the direction [5,6]. On the contrary, the addition of $30 \mathrm{wt} . \%$ of cork maintained or improved, respectively, the tensile modulus of SPCL and PCL matrices, as shown in Table 2.

\subsection{Morphology}

The fracture surface after mechanical tests of the injection moulded specimens, obtained by scanning electron microscopy (SEM), are shown in Fig. 5.

In the micrographs obtained at high magnification, it is possible to observe two distinct behaviours. The polyesters PLLA and PHBV reveals fragile fracture while the PCL and SPCL shows a ductile fracture. Regarding the biocomposites SEM micrographs, based on PLLA and PHBV matrices, the cork fracture and the absence of voids or cavities denote efficient stress transfer from the matrix when the load is applied. Thus, the results suggest good physical bonding between cork and the different bio-based polyesters without the use of coupling agent or chemical treatment. This result also confirms that the observed reduction in terms of weight in the biocomposites was obtained by the presence of cork and not by the presence of voids in the bio-based matrix or between the composite constituents after the injection moulding process. In the case of the biocomposites based on PCL or SPCL the stretching of the PCL matrix was not observed that is in accordance with the reduction of strain after the mechanical tests. Combining a matrix containing starch (SPCL) with cork resulted in a more complex biocomposite indicated as SPCL/Cork.

As show in the micrograph, the fracture reveals the negative shape of the cork cells and some micro crack between the corkmatrix not observed in the previous biocomposites. This is indicative of the lack of adhesion between the different components that compose the biocomposite, however, does not significantly compromises the mechanical properties as discussed above.

\subsection{Thermal analysis}

\subsubsection{Thermogravimetric analysis (TGA)}

The influence of cork on the thermal stability of the injection moulded biocomposites and the stability of the polyesters was studied by thermogravimetric analysis (TGA) essays. TGA results and the respective derivative thermogravimetric curves (DTG) are shown in Fig. 6. The initial degradation temperature (Tonset), maximum peaks obtained in the DTG curve and the ash content are shown in Table 3.

The thermal degradation process of PLLA, PHBV and its biocomposites occurs in only one weight loss step, while for the PCL, SPCL and its biocomposites a multi-step degradation process was observed. In the presence of cork the curves are shifted to lower temperatures indicating a small decreasing in the thermal stability of the biocomposite. The only exception was with PHBV, where the addition of cork improved the initial thermal stability. This small increase on the thermal stability occurred despite cork presented the lowest Tonset $\left(246.3^{\circ} \mathrm{C}\right)$ as compared with the used polyester matrices (see Table 3). Some recent studies evidenced that the addition of nano-clay and natural fibres reduced or maintain, respectively, the thermal stability of PHBV [33,34]. However in the present study cork promoted a slight increase in $5.5 \%$ of the initial degradation temperature. Furthermore, during the injection moulding process it was observed that PHBV presents a slower cooling rate, inducing some warping in the samples that was ameliorated by the addition of cork. The TGA curves and Table 3 showed that thermal decomposition of SPCL started at $309^{\circ} \mathrm{C}$ with the decomposition of starch and continued at $411^{\circ} \mathrm{C}$ with the degradation of the PCL fraction. Comparing the effect of cork and starch on the PCL matrix, Fig. 6(c) shows that cork revealed higher thermal stability than starch. This result was also confirmed by the DTG curve of Fig. 6(d) with the intense peaks appearing at $318.4{ }^{\circ} \mathrm{C}$ for SPCL and $323.6^{\circ} \mathrm{C}$ for PCL/Cork.

The TGA curves and the results of Table 3 indicated that thermal degradation of biocomposites is a combined phenomenon of thermal degradation of each of the components; i.e., the selected matrix and the granulated cork. The TGA findings also suggested that cork was the last material to be degraded, showing a slower thermal degradation to the biocomposites at higher temperatures, resulting in a lower weight loss rate and higher ash content, from $6.3 \%$ up to $9.3 \%$.

\subsubsection{Differential scanning calorimetry (DSC)}

DSC analysis also provides relevant information about the thermal and structural characteristics of materials. In this study, DSC was performed to understand the effect of the cork addition to the matrix, using for that the second heating scan. Thus, we are erasing any previous thermal story through the first heating cycle. The onset values of phase transition temperatures (crystallization temperature $T_{c}$, cold crystallization temperature $T_{c c}$ and melting temperature $T_{m}$ ), glass transition temperature $T_{g}$ at the mid-point of heat capacity changes and enthalpies $\left(\Delta H_{c c}\right.$, cold crystallization enthalpy, $\Delta H_{m}$, melting enthalpy and $\Delta H_{c}$, crystallization enthalpy) recorded by DSC of the injection moulded materials are summarized in Table 4. The thermograms are shown in Fig. 7.

In this study, we observed that the PLLA, PHBV and the respective biocomposites (Fig. 7(a)) displayed on heating three main transitions: glass transition, a cold crystallization exothermic followed by a melting endothermic event. We also assessed the influence of cork on the $T_{g}$ of the PLLA and PHBV polyesters. It has been found that $T_{g}$ was slightly affected by the composition, with a small increase with the cork content, from 57.3 to $58.4^{\circ} \mathrm{C}$ and -0.6 to $4.6{ }^{\circ} \mathrm{C}$ (see Table 4), suggesting confinement of the mobile amorphous phase. This finding, previously observed in the PHB using a different type of natural fibres [38], was explained by an intermolecular interaction between carbonyl $(-\mathrm{C}=\mathrm{O})$ groups of the PHBV and hydroxyl $(-\mathrm{OH})$ groups of the natural fibre that decreases the molecular flexibility of the polymer chains involved in the glass transition. The PLLA was found to present an amorphous structure that might be related with the previous DSC 

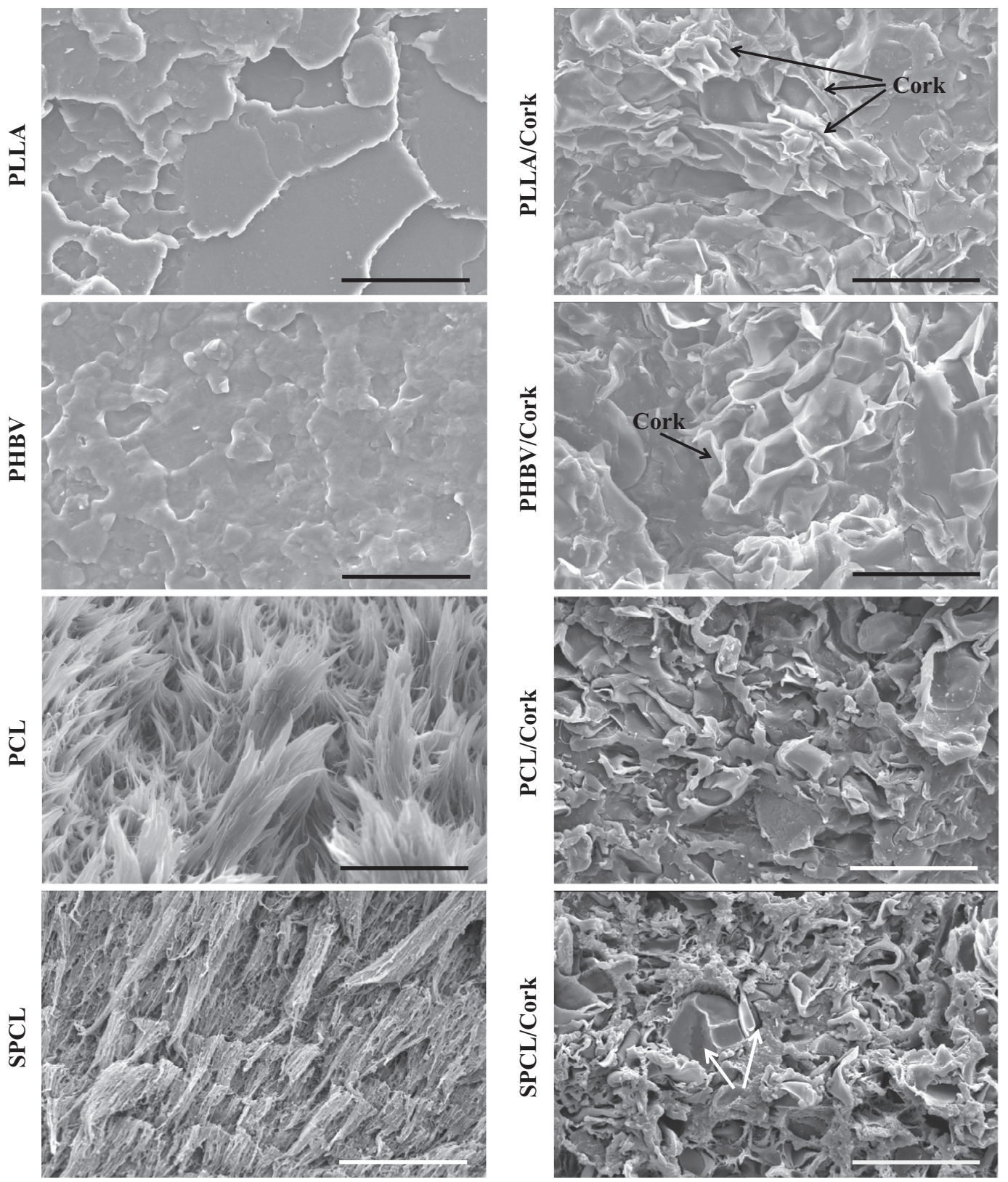

Fig. 5. Morphology of the fracture of the injection moulding specimens after tensile tests. Scale bar indicates $50 \mu \mathrm{m}$.

cooling process at $20^{\circ} \mathrm{C} / \mathrm{min}$ that could prevent crystallization of the material. In the case of the PLLA thermogram, the cold crystallization temperature peak was shifted to lower temperature with the addition of cork. This agrees with the finds in the literature [39] that the presence of some lignocellulosic materials such as wood can promote the initial cold crystallization temperature of the PLLA matrix. Moreover, the thermograms of the PLLA and PHBV show a single melting temperature peak event at $160.5^{\circ} \mathrm{C}$ and $170^{\circ} \mathrm{C}$, respectively. For the biocomposites PLLA/Cork and PHBV/Cork the maximum melting peak occurs at a high temperature being $166.4^{\circ} \mathrm{C}$ and $171.2^{\circ} \mathrm{C}$, respectively. Moreover, for the biocomposites it was observed a second melting peak with both smaller intensity and lower temperature. The presence of two melting peaks almost completely overlapped can be associated to the presence and reorganization of a different type of crystals with higher order degree and stability [40]. The onset temperature of the crystallisation during the cooling tends to show a slight but not significant increase with the cork content in the semi-crystalline PCL and SPCL. In PCL the $T_{c}$ was found to occur at $29.6{ }^{\circ} \mathrm{C}$ and for $\mathrm{PCL} / \mathrm{Cork}$ at $29.1^{\circ} \mathrm{C}$, while the SPCL and SPCL/Cork showed it at 27.5 and $28.1^{\circ} \mathrm{C}$, respectively. We observed that the heat of crystallization and the heat of melting of the bio-based matrices in all the biocomposites increased with the addition of cork, indicating an improvement in the degree of crystallinity $\left(\chi_{c}\right)$ as shown in Table 4 . These findings suggest that cork may have the ability to modify the crystallisation by increasing the number of nucleating sites in the bio-based polyesters and enhancing its crystallinity degree. This positive effect was not observed in a previous work of Vilela et al. [24] where the cork residues were compounded with bio-based matrices through a melt mixer to produce the pellets. Thus, twin-screw extrusion brings advantages in the preparation of the cork biocomposite pellets to be further used 

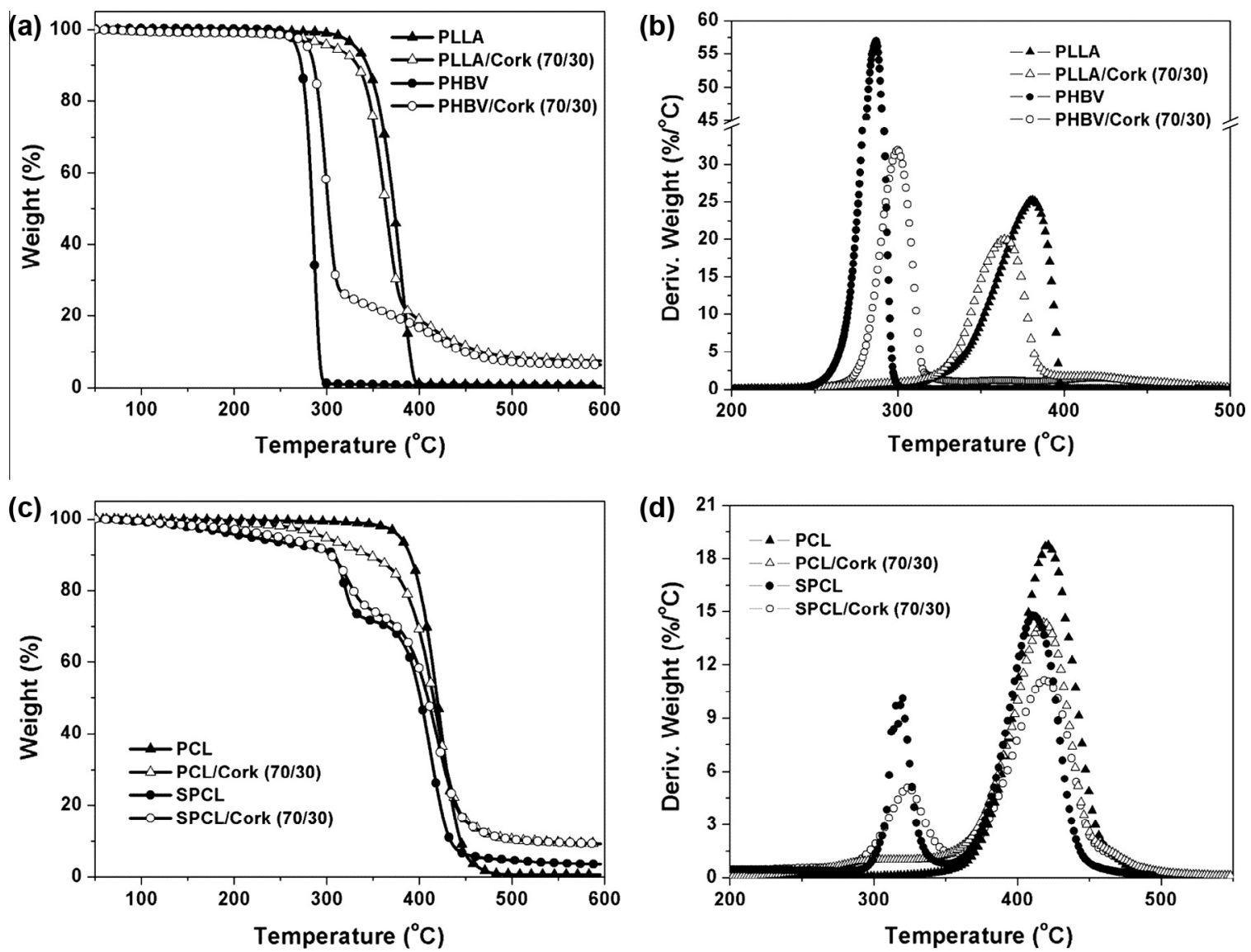

Fig. 6. Thermogravimetric curves of the neat polymers and the biocomposites.

Table 3

The initial degradation temperatures, the peak temperatures, and ash content of the neat polymers and its biocomposites with cork obtained by TGA.

\begin{tabular}{|c|c|c|c|c|c|}
\hline Sample & \multicolumn{2}{|c|}{ Tonset $\left({ }^{\circ} \mathrm{C}\right)$} & \multicolumn{2}{|c|}{$\begin{array}{l}\text { DTG peak } \\
\text { temperatures } \\
\left({ }^{\circ} \mathrm{C}\right)\end{array}$} & Ash content (\%) \\
\hline PLLA & 341.7 & & 380.6 & & 0.6 \\
\hline PLLA/Cork & 335.8 & & 364.4 & & 7.4 \\
\hline PHBV & 269.3 & & 286.8 & & 0.4 \\
\hline PHBV/Cork & 284.2 & & 299.8 & & 6.3 \\
\hline PCL & 387.7 & & 421.0 & & 0.5 \\
\hline PCL/Cork & 266.9 & 387.0 & $293.8^{\mathrm{a}}$ & 418.6 & 9.3 \\
\hline SPCL & 309.6 & 382.3 & 318.4 & 411.4 & 4.8 \\
\hline SPCL/Cork & 303.7 & 386.6 & 323.6 & 418.9 & 9.3 \\
\hline Cork & 246.3 & 380.0 & 292.9 & 414.3 & 19.8 \\
\hline
\end{tabular}

a Very small intensity peak.

in injection moulding. Moreover, the addition of starch to the PCL reduced the crystallinity in $5.8 \%$, thus contributing to enhancing the biodegradation.

\section{Conclusions}

This study dealt with the mechanical, morphological and thermal properties of biodegradable polyester biocomposites containing granulated cork (30 wt.\%) processed by extrusion followed by injection moulding. This environmental friendly approach of using a renewable material such as natural cork, promoted a reduction of PLLA and PHBV density resulting in lightweight biocomposites. The mechanical properties shows that the use of cork does not compromise significantly the final properties under tensile load and the morphology reveals a good physical bonding of cork to the bio-based polyester matrices. The thermal properties by TGA
Table 4

Melting temperatures and enthalpies, crystallization temperatures, and crystallinity degrees of the bio-based composites containing cork, obtained by DSC.

\begin{tabular}{|c|c|c|c|c|c|c|c|c|}
\hline \multirow[b]{2}{*}{ Sample } & \multicolumn{2}{|c|}{ 1st cooling } & \multicolumn{5}{|c|}{ 2nd heating } & \multirow[t]{2}{*}{$\chi_{c}^{\mathrm{a}}(\%)$} \\
\hline & $\begin{array}{l}T_{c} \\
\left({ }^{\circ} \mathrm{C}\right) \\
\end{array}$ & $\begin{array}{l}\Delta H_{c} \\
(\mathrm{~J} / \mathrm{g})\end{array}$ & $\begin{array}{l}T_{g} \\
\left({ }^{\circ} \mathrm{C}\right)\end{array}$ & $\begin{array}{l}T_{c c} \\
\left({ }^{\circ} \mathrm{C}\right)\end{array}$ & $\begin{array}{l}\Delta H_{c c} \\
(\mathrm{~J} / \mathrm{g})\end{array}$ & $\begin{array}{l}T_{m} \\
\left({ }^{\circ} \mathrm{C}\right)\end{array}$ & $\begin{array}{l}\Delta H_{m} \\
(\mathrm{~J} / \mathrm{g})\end{array}$ & \\
\hline PLLA & & & 57.3 & 108.8 & -42.4 & 155.3 & 44.6 & 2.3 \\
\hline PLLA/Cork & & & 58.4 & 105.9 & -40.8 & 154.2 & 47.5 & 7.2 \\
\hline PHBV & & & -0.6 & 47.1 & -68.9 & 160.6 & 94.6 & 17.5 \\
\hline PHBV/Cork & & & 4.6 & 98.2 & -67.1 & 153.7 & 97.1 & 20.6 \\
\hline PCL & 29.6 & 62.2 & & & & 50.3 & 69.4 & 49.7 \\
\hline PCL/Cork & 29.1 & 69.0 & & & & 50.1 & 80.1 & 57.4 \\
\hline SPCL & 27.5 & 64.1 & & & & 49.2 & 61.2 & 43.9 \\
\hline SPCL/Cork & 28.1 & 66.2 & & & & 50.3 & 64.7 & 46.4 \\
\hline
\end{tabular}

a Crystallinity degree calculated on the basis of a $100 \%$ crystalline polymer a melting enthalpy of $\Delta H_{m}^{0}=93 \mathrm{~J} / \mathrm{g}$ corresponding to poly(L-lactic acid) (PLLA) [35]; $146 \mathrm{~J} / \mathrm{g}$ for polyhydroxybutyrate-co-hydroxyvalerate (PHBV) [36] and $139.5 \mathrm{~J} / \mathrm{g}$ for poly- $\varepsilon$-caprolactone (PCL) [37].

showed that cork presents higher thermal stability than starch. Regarding the degree of crystallinity, the DSC analyses revealed an opposite effect from both fillers were starch contributed to an increase of the amorphous phase leading to a higher biodegradation. Moreover, DSC data have confirmed the positive effect on the use of cork that increases the crystallinity degree for all the used bio-based polyester matrices.

Besides the cost reduction of bio-based matrices by adding cork, it is possible to provide aesthetic characteristics, or reduce matrix weight or even increase stiffness depending of the used biodegradable polymer. Cork biocomposites are good candidates for the production of sustainable products promoting added-value to cork for a wide range of applications. 

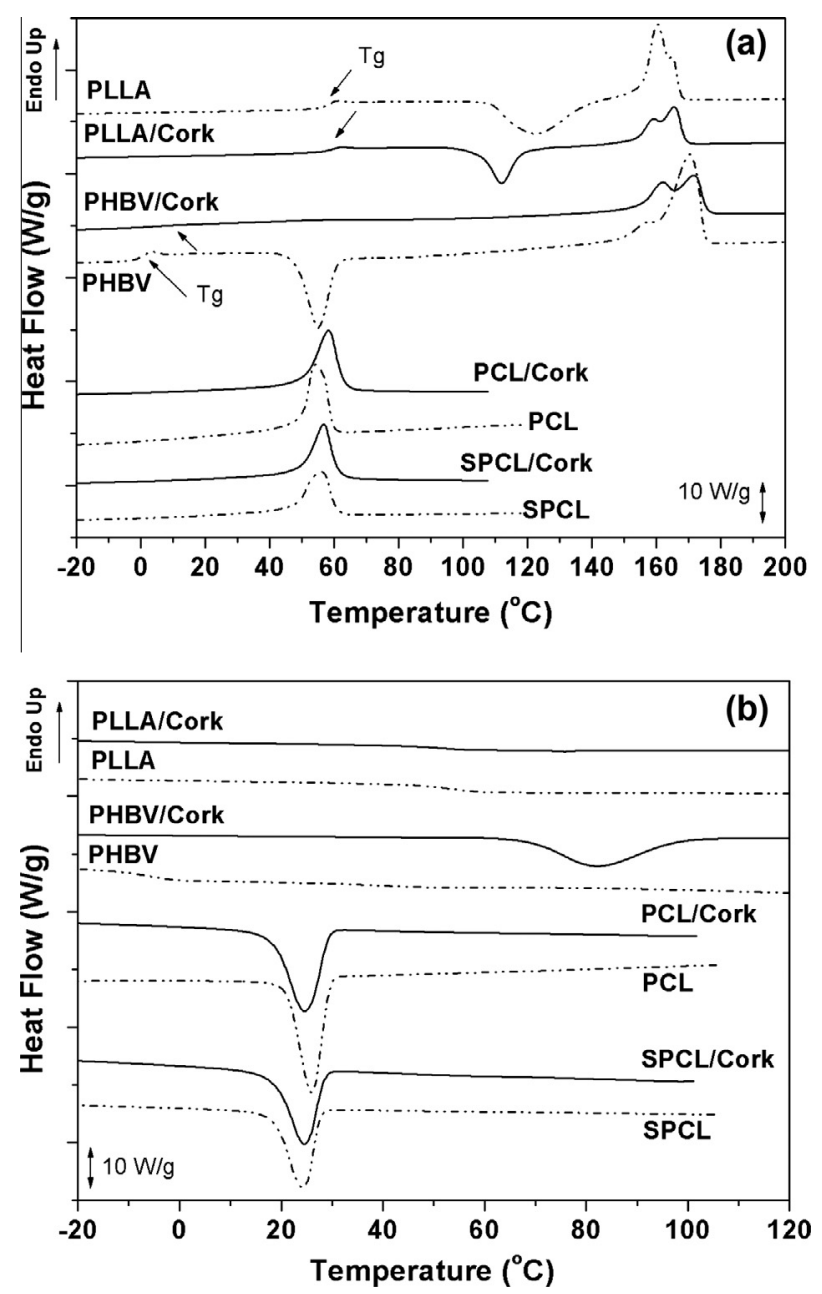

Fig. 7. DSC thermograms of the biobased composites with cork at $20^{\circ} \mathrm{C} \mathrm{min}^{-1}$ showing: (a) the second heating and (b) the first cooling.

\section{Acknowledgments}

The work was performed within the project of Corticeira Amorim S.G.P.S. on the development of new products based in/with cork. The authors gratefully acknowledge the financial support, through the COMPETE/QREN/EU funding program in the project with acronym NovelComp (QREN FCOMP-01-0202FEDER-003107). The author E.M.F. acknowledges the financial support from the Portuguese Foundation for Science and Technology (FCT) and POPH/FSE for the post-doctoral grant (SFRH/BPD/96197/2013).

\section{References}

[1] M.J. John, S. Thomas, Biofibres and biocomposites, Carbohydr. Polym. 71 (2008) 343-364.

[2] K.G. Satyanarayana, G.G.C. Arizaga, F. Wypych, Biodegradable composites based on lignocellulosic fibers-an overview, Prog. Polym. Sci. 34 (2009) $982-$ 1021.

[3] O. Faruk, A.K. Bledzki, H.-P. Fink, M. Sain, Biocomposites reinforced with natural fibers: 2000-2010, Prog. Polym. Sci. 37 (2012) 1552-1596.

[4] L. Yu, K. Dean, L. Li, Polymer blends and composites from renewable resources, Prog. Polym. Sci. 31 (2006) 576-602.

[5] S.P. Silva, M.A. Sabino, E.M. Fernandes, V.M. Correlo, L.F. Boesel, R.L. Reis, Cork: properties, capabilities and applications, Int. Mater. Rev, 50 (2005) 345-365.

[6] H. Pereira, Cork: Biology, Production and Uses, Elsevier, Amsterdam, 2007.

[7] L. Gil, Moiteiro C. Cork, Ullmann's Encyclopedia of Industrial Chemistry, WileyVCH Verlag GmbH \& Co. KGaA, 2000.

[8] L. Gil, Cork Compos.: A Rev. Mater. 2 (2009) 776-789.

[9] L.J. Gibson, Cellular solids, MRS Bull. 28 (2003) 270-274.

[10] J.F. Mano, The viscoelastic properties of cork, J. Mater. Sci. 37 (2002) 257-263.
[11] M.A. Fortes, M. Teresa Nogueira, The poison effect in cork, Mater. Sci. Eng., A 122 (1989) 227-232.

[12] R.T. Jardin, F.A.O. Fernandes, A.B. Pereira, R.J. Alves de Sousa, Static and dynamic mechanical response of different cork agglomerates, Mater. Des. 68 (2015) 121-126.

[13] E.M. Fernandes, V.M. Correlo, J.A.M. Chagas, J.F. Mano, R.L. Reis, Cork based composites using polyolefin's as matrix: morphology and mechanical performance, Compos. Sci. Technol. 70 (2010) 2310-2318.

[14] E.M. Fernandes, V.M. Correlo, J.A.M. Chagas, J.F. Mano, R.L. Reis, Properties of new cork-polymer composites: advantages and drawbacks as compared with commercially available fibreboard materials, Compos. Struct. 93 (2011) 3120 3129.

[15] E.M. Fernandes, V.M. Correlo, J.F. Mano, R.L. Reis, Polypropylene-based corkpolymer composites: processing parameters and properties, Compos. Part BEng. 66 (2014) 210-223.

[16] F.B. Abdallah, R.B. Cheikh, M. Baklouti, Z. Denchev, A.M. Cunha, Effect of surface treatment in cork reinforced composites, J. Polym. Res. 17 (2010) 519-528.

[17] J. Abenojar, A.Q. Barbosa, Y. Ballesteros, J.C. del Real, L.F.M. da Silva, M.A. Martinez, Effect of surface treatments on natural cork: surface energy, adhesion, and acoustic insulation, Wood Sci. Technol. 48 (2014) 207-224.

[18] A.D. La Rosa, G. Recca, J. Summerscales, A. Latteri, G. Cozzo, G. Cicala, Bio-based versus traditional polymer composites. A life cycle assessment perspective, J. Cleaner Prod. 74 (2014) 135-144.

[19] B. Hachemane, R. Zitoune, B. Bezzazi, C. Bouvet, Sandwich composites impact and indentation behaviour study, Compos. Part B-Eng. 51 (2013) 1-10.

[20] O. Castro, J.M. Silva, T. Devezas, A. Silva, L. Gil, Cork agglomerates as an ideal core material in lightweight structures, Mater. Des. 31 (2010) 425-432.

[21] E.M. Fernandes, V.M. Correlo, J.F. Mano, R.L. Reis, Novel cork-polymer composites reinforced with short natural coconut fibres: effect of fibre loading and coupling agent addition, Compos. Sci. Technol. 78 (2013) 56-62.

[22] E.M. Fernandes, J.F. Mano, R.L. Reis, Hybrid cork-polymer composites containing sisal fibre: morphology, effect of the fibre treatment on the mechanical properties and tensile failure prediction, Compos. Struct. 105 (2013) 153-162.

[23] E.M. Fernandes, V.M. Correlo, J.F. Mano, R.L. Reis, Innovative bio-based composites comprising cork and biodegradable polyester, in: J.A.M. Ferreira (Ed.), 16th International Conference on Composite Structures (ICCS16). FEUP, Porto, 2011.

[24] C. Vilela, A.F. Sousa, C.S.R. Freire, A.J.D. Silvestre, C. Pascoal Neto, Novel sustainable composites prepared from cork residues and biopolymers, Biomass Bioenergy 55 (2013) 148-155.

[25] L.Y. Ljungberg, Materials selection and design for development of sustainable products, Mater. Des. 28 (2007) 466-479.

[26] A.K. Mohanty, M. Misra, G. Hinrichsen, Biofibres, biodegradable polymers and biocomposites: an overview, Macromol. Mater. Eng. 276-277 (2000) 1-24.

[27] A.K. Mohanty, M. Misra, L.T. Drzal, Sustainable bio-composites from renewable resources: opportunities and challenges in the green materials world, J. Polym. Environ. 10 (2002) 19-26.

[28] E.M. Fernandes, R.A. Pires, J.F. Mano, R.L. Reis, Bionanocomposites from lignocellulosic resources: properties, applications and future trends for their use in the biomedical field, Prog. Polym. Sci. 38 (2013) 1415-1441.

[29] European Bioplastics, Institute for Bioplastics and Biocomposites, novaInstitute, 2014 <http://en.european-bioplastics.org/market/>.

[30] L. Avérous, Biodegradable multiphase systems based on plasticized starch: a review, J. Macromol. Sci., Part C 44 (2004) 231-274.

[31] G. Bogoeva-Gaceva, M. Avella, M. Malinconico, A. Buzarovska, A. Grozdanov, G. Gentile, et al., Natural fiber eco-composites, Polym. Compos. 28 (2007) 98107.

[32] R.A. Gross, B. Kalra, Biodegradable polymers for the environment, Science 297 (2002) 803-807.

[33] R. Thire, L.C. Arruda, L.S. Barreto, Morphology and thermal properties of poly(3-hydroxybutyrate-co-3-hydroxyvalerate)/attapulgite nanocomposites, Mater. Res.-Ibero-Am. J. Mater. 14 (2011) 340-344.

[34] P. Russo, C. Carfagna, F. Cimino, D. Acierno, P. Persico, Biodegradable composites reinforced with kenaf fibers: thermal, mechanical, and morphological issues, Adv. Polym. Technol. 32 (2013) 313-322.

[35] E.W. Fischer, H.J. Sterzel, G. Wegner, Investigation of structure of solution grown crystals of lactide copolymers by means of chemical-reactions, Colloid Polym. Sci. 251 (1973) 980-990.

[36] S. Gogolewski, M. Jovanovic, S.M. Perren, J.G. Dillon, M.K. Hughes, The effect of melt-processing on the degradation of selected polyhydroxyacids: polylactides, polyhydroxybutyrate, and polyhydroxybutyrate-co-valerates, Polym. Degrad. Stab. 40 (1993) 313-322.

[37] V. Crescenzi, G. Manzini, G. Calzolari, C. Borri, Thermodynamics of fusion of poly- $\beta$-propiolactone and poly- $\epsilon$-caprolactone. comparative analysis of the melting of aliphatic polylactone and polyester chains, Eur. Polym. J. 8 (1972) 449-463.

[38] M. Avella, E. Martuscelli, B. Pascucci, M. Raimo, B. Focher, A. Marzetti, A new class of biodegradable materials: poly-3-hydroxy-butyrate/steam exploded straw fiber composites. I. Thermal and impact behavior, J. Appl. Polym. Sci. 49 (1993) 2091-2103.

[39] S. Pilla, S. Gong, E. O'Neill, L. Yang, R.M. Rowell, Polylactide-recycled wood fiber composites, J. Appl. Polym. Sci. 111 (2009) 37-47.

[40] R. Masirek, Z. Kulinski, D. Chionna, E. Piorkowska, M. Pracella, Composites of poly(L-lactide) with hemp fibers: morphology and thermal and mechanical properties, J. Appl. Polym. Sci. 105 (2007) 255-268. 